

\section{Granuloma annulare: report of 13 patients treated with photodynamic therapy}

Dear Editor,

Granuloma annulare (GA) is a benign inflammatory granulomatous skin. ${ }^{1}$ Photodynamic therapy (PDT) has been described as another therapeutic option for localized GA, with a degree of recommendation $\mathrm{B}^{2}{ }^{2}$ Therefore, we have carried out a review of all patients with GA treated with PDT in our Dermatology Unit.

We performed a retrospective observational study in San Jorge Hospital (Huesca, Spain) including all patients diagnosed with GA and treated with PDT between 2007 and 2018. Diagnosis of GA was clinical and a skin biopsy was performed if it was necessary. In all patients, methyl aminolevulinate (MAL) or aminolevulinic acid (ALA) was applied under occlusive and opaque dressing for $3 \mathrm{~h}$ and illuminated with LED $635 \mathrm{~nm}$ (Aktilite ${ }^{\circledR}$, Uppsala, Sweden) with a fluence of $37 \mathrm{~J} / \mathrm{cm}^{2}$. The lesions were prepared by a soft curettage or microneedling, and some lesions did not receive any kind of prior skin preparation. Continuous variables were described using means and standard deviations. Statistical analyses were carried out using SPSS software (version 20.0; IBM Corp, Armonk, NY, USA).

Thirteen patients were included in the study (Table 1). Eleven cases $(84.6 \%)$ were women and two men $(15.4 \%)$, with a mean of 53 years old. Eighty-four per cent patients $(n=11)$ underwent a previous biopsy to confirm the diagnosis of GA. The majority received a pretreatment with curettage $(38.5 \%, n=5)$ or microneedling $(46.2 \%, n=6)$. Seven patients $(53.8 \%)$ responded completely to PDT and four partially improved (30.8\%) (Fig. 1). Of the total of responding patients and those who improved, $9(81.81 \%)$ were treated with MAL, 1 (9.09\%) with ALA and 1 (9.09\%) with both.. With regard to the number of sessions, the majority received between one and three sessions separated by four weeks with MAL. Seventy per cent $(n=9)$ tolerated the PDT session quite well, and 30\% $(n=4)$ reported moderate pain. Cosmetic result was excellent in all patients with clinical remission, with just a slight hyperpigmentation in two patients who have complete response.

To our knowledge, there are few articles analysing the effectiveness of PDT for GA. The majority are isolated clinical cases ${ }^{3,4}$ or series of clinical cases, ${ }^{5,6}$ and they are summarized in table 1 . The largest one was published by Calzavara-Pinton et al. ${ }^{7}$ in a retrospective analysis of real-life practice of off-label PDT using MAL.
Compared PDT effectiveness with other treatments, for example intralesional corticosteroids, this obtained complete clearance of $70 \%$ of the patients compared with the $44 \%$ of placebo. ${ }^{2}$ Concerning cryosurgery, the response rate was $80 \%$ with a single freeze-thaw cycle in a clinical trial including 31 patients but cosmetic results with cryosurgery were good only in 11 patients $(39.3 \%)$ and crioatrophy occurred in four patients $(21.1 \%){ }^{8}$

The cellular photodamage after PDT involves different death pathways. The result of MAL-PDT depends on the thickness of corner layer and epidermis, in inflammatory cutaneous diseases with mononuclear and lymphocytic infiltration. ${ }^{7}$ ALA-PDT has been demonstrated to induce in vivo apoptosis in lesional Tlymphocytes in psoriatic plaques. ${ }^{9}$ The etiopathogenesis of GA is still unknown, but some authors propose that T-helper cells have an interaction with histiocytes and this leads to granuloma formation. In addition, these $\mathrm{T}$ cells express interferon gamma and the aggressive macrophages express tumour necrosis factor (TNF- $\alpha$ ) and matrix metalloproteinases that contribute to inflammation and destruction. ${ }^{1}$ Therefore, to try to obtain a good response and that apoptosis occurs in T-lymphocytes, it is important to pretreat the skin lesion that favours the penetration of the photosensitizer.

In conclusion, the efficacy of PDT in localized GA is similar to other more established treatments and without adverse effects. Until a clinical trial shows its real efficacy, PDT could be considered after failure of other easier and cheaper treatments such as topical or intralesional corticosteroids and maybe before cryotherapy in order to avoid permanent scars.

\section{Acknowledgement}

The patients in this manuscript have given written informed consent to the publication of their case details.

\section{Conflicts of interest}

The authors have no conflict of interest to declare.

\section{Funding source}

This article has no funding source.

\section{A.J. García-Malinis, ${ }^{1, *}$ iD T. Gracia-Cazaña, ${ }^{2}$ D. Planas Linares, ${ }^{1}$ P.J. Agón-Banzo, ${ }^{3}$ Y. Gilaberte ${ }^{4}$ (D}

${ }^{1}$ Unit of Dermatology, Hospital San Jorge, Huesca, Spain, ${ }^{2}$ Unit of Dermatology, Barbastro Hospital, Barbastro, Huesca, Spain, ${ }^{3}$ Perpetuo Socorro HealthCare Center, Huesca, Spain, ${ }^{4}$ Department of Dermatology, University Hospital Miguel Servet, Zaragoza, Spain ${ }^{*}$ Correspondence: A.J. García Malinis. E-mail: ajgarciamalinis@ gmail.com 


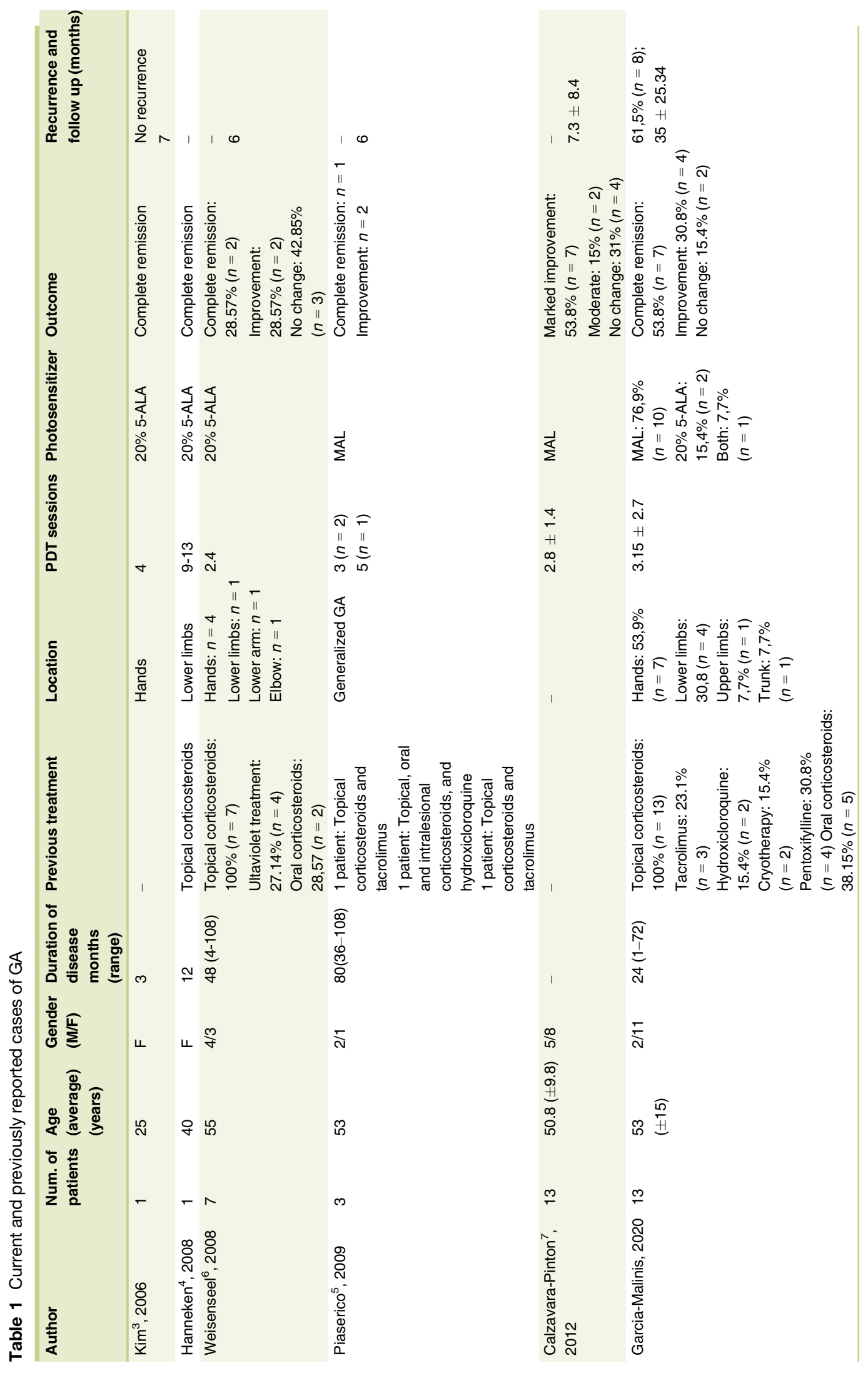




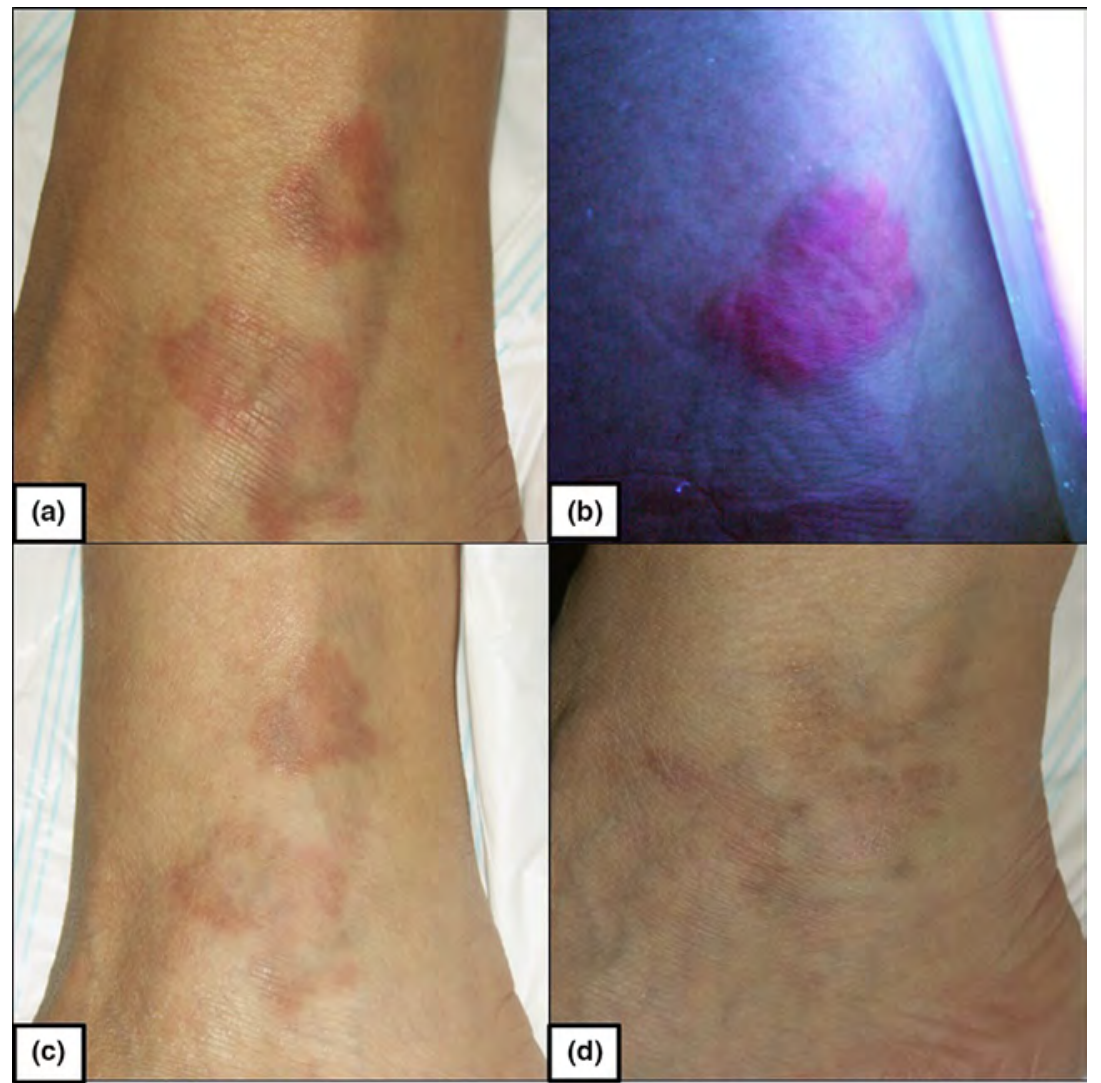

Figure 1 (a) Granuloma annulare (GA) in lower limbs. (b) Fluorescence before photodynamic therapy (PDT) session. (c) Hyperpigmentation 1 month later after two sessions of PDT separated by 4 weeks. (d) Complete resolution of GA

\section{References}

1 Piette EW, Rosenbach M. Granuloma annulare: Pathogenesis, disease associations and triggers, and therapeutic options. J Am Acad Dermatol 2016; 75: $467-479$

2 Wang J, Khachemoune A. Granuloma annulare: a focused review of therapeutic options. Am J Clin Dermatol 2018; 19: 333-344.

3 Kim YJ, Kang HY, Lee ES, Kim YC. Successful treatment of granuloma annulare with topical 5-aminolaevulinic acid photodynamic therapy. $J$ Dermatol 2006; 33: 642-643.

4 Hanneken S, Schulte KW, Neumann NJ. [Photodynamic therapy of granuloma annulare]. Hautarzt Z Dermatol Venerol Verwandte Geb 2008; 59: 283-285.

5 Piaserico S, Zattra E, Linder D, Peserico A. Generalized granuloma annulare treated with methylaminolevulinate photodynamic therapy. Dermatology 2009; 218: 282-284.

6 Weisenseel P, Kuznetsov AV, Molin S, Ruzicka T, Berking C, Prinz JC. Photodynamic therapy for granuloma annulare: more than a shot in the dark. Dermatology 2008; 217: 329-332.
7 Calzavara-Pinton PG, Rossi MT, Aronson E, Sala R, Italian Group For Photodynamic Therapy. A retrospective analysis of real-life practice of off-label photodynamic therapy using methyl aminolevulinate (MAL-PDT) in 20 Italian dermatology departments. Part 1: inflammatory and aesthetic indications. Photochem Photobiol Sci 2013; 12: $148-157$.

8 Blume-Peytavi U, Zouboulis CC, Jacobi H, Scholz A, Bisson S, Orfanos CE. Successful outcome of cryosurgery in patients with granuloma annulare. Br J Dermatol 1994; 130: 494-497.

9 Bissonnette R, Tremblay J-F, Juzenas P, Boushira M, Lui H. Systemic photodynamic therapy with aminolevulinic acid induces apoptosis in lesional T lymphocytes of psoriatic plaques. J Invest Dermatol 2002; 119: $77-83$.

\section{DOI: 10.1111/jdv.16935}

